\title{
Getting Science to the Citizen - 'Food Addiction' at the British Science Festival as a Case Study of Interactive Public Engagement with High Profile Scientific Controversy
}

\author{
Sue P. Bird ${ }^{a} \quad$ Michelle Murphy ${ }^{a} \quad$ Tina Bake $^{a}$ Özgür Albayrak ${ }^{b}$ \\ Julian G. Mercer ${ }^{a}$ \\ ${ }^{a}$ Rowett Institute of Nutrition and Health, University of Aberdeen, Aberdeen, UK, \\ ${ }^{\mathrm{b}}$ Department of Child and Adolescent Psychiatry, Psychotherapy and Psychosomatics, \\ University of Duisburg-Essen, Essen, Germany
}

\section{Introduction}

As the pace of advance in biomedical science continues to quicken, it is increasingly important for scientists to engage directly with the public, and indeed many funding bodies are beginning to require their funded researchers to participate in public engagement activities.

In the UK, the concept of engaging the public with science was largely initiated by the publication of 'Science and Society' by the House of Lords Select Committee on Science and Technology in 2000. This publication changed the science communication landscape from one in which the public were viewed as deficient in knowledge and understanding of science, to one in which scientists and members of the community were to be regarded as on equal terms in a dialogue and two-way exchange of knowledge and ideas. The support for public engagement programmes, or science in society, in the UK continues to grow and be recognised, and has acted as a model for many other countries in Europe because of the involvement of such institutions as the British Science Association (www.britishscienceassociation.org) which was founded in 1831 and is a charity which 'exists to advance the public understanding, accessibility and accountability of the sciences and engineering in the UK', and the National Co-ordinating Centre for Public Engagement (www.publicengagement.ac.uk). Both these web sites contain extensive practical 'how to' resources and background and history to the development of science in society in the UK. Successful communication of science can take many forms, depending on situation and interest group, and detailed discussions of engagement 
activities and outcomes from academic, commercial and media perspectives are available in an accessible format [1].

The EU has not been slow to realise the importance and value of public engagement with the science it funds. Since the Framework Programme 6 (FP6) funding round, the beneficiaries of EU funding are also expected to undertake engagement activity and all FP7 projects (such as the NeuroFAST project referred to in this editorial) have to submit a dissemination plan as part of the proposal, which is now a formal part of the evaluation of the project.

The two main reasons for encouraging the public to engage with scientific research cited by the Commission via the Science in Society portal ( http://tiny.cc/obesity2013) are:

1) Ensuring that the right policy decisions are made by the Commission by facilitating appropriate dialogue between scientists, the public and policy stakeholders; and

2) Increase the number of people who choose to study scientific subjects and work in research and scientific careers.

The EU also provides a great deal of support for its project participants to assist with their engagement strategies - for instance, 'Communicating EU Research \& Innovation - a Guide for Project Participants' available at http://ec.europa.eu/research/social-sciences/pdf/ communicating-research_en.pdf and at the site 'Successful Communications' http://ec.europa. eu/research/science-society/science-communication/index_en.htm [2].

This engagement should be directed towards explaining and putting into context the complexities and implications of biological systems and their functionality. Otherwise, it will be left to the popular media to be the sole source of such information. Engagement in public debate both allows individual scientists to present their science in a measured, contextual way, free from the distraction of a sensational headline, and also gives members of the public access to scientists who, to all intents and purposes, they are commissioning to perform research on their behalf. Many scientists shy away from this sort of interaction, and public engagement in areas of scientific controversy can also be seen as threatening.

To address some of these issues, this case study describes a public engagement event initiated and presented by scientists from the EU-funded NeuroFAST project as part of the British Science Festival held in Aberdeen, Scotland, in September 2012. The members of this EU project have recently published a special issue titled 'Food Addiction: Fact or Fiction - the NeuroFAST Project' in OBESITY FACTS [3]. The event addressed the controversial and high profile area of 'food addiction', a topic that has received a lot of attention in the popular media in the last decade, reflecting the commitment of the European Commission and the NeuroFAST project to engage the public in dialogue about funded science.

\section{Food Addiction}

The concept that people might be addicted to food has been widely touted in the popular media by way of partial explanation of some interactions with contemporary palatable foods, the overconsumption of calories and the attendant onward march of the obesity epidemic in the developed world. This media coverage, based on publications in the scientific literature, has given this topic a high profile in terms of public awareness. However, this is an area of scientific controversy, with many scientists being uncomfortable with the casual manner with which the terminology 'food addiction' is bandied about. This is also an area of active international research effort, as exemplified by the funding from the European Union for the current NeuroFAST research programme, which was designed to expand the evidence base for or against food addiction and answer the question 'Does food addiction exist?'. The scientific content of the NeuroFAST project reflects the common ground in terms of neurochemical pathways and brain regions between eating behaviour, including eating disorders, and 
addiction biology $[4,5]$. With this background, NeuroFAST scientists proposed an event on the topic of 'food addiction' to the British Science Festival.

\section{The Concept and the Opportunity}

There are many different ways of engaging people with research - from lectures, exhibitions and shows to more interactive and discursive forms of engagement such as informal 'café' settings for discussions and interactive workshops. Excellent resources and explanations of these engagement models can be found on the web sites of the British Science Association (www.britishscienceassociation.org/science-society/useful-links-and-further-reading) and the National Co-Ordinating Centre (www.publicengagement.ac.uk/).

The British Science Festival is held every year in a different city in the UK. The Festival is organised by the British Science Association, and is one of Europe's largest celebrations of science, engineering and technology. Over 250 events, activities, exhibitions and trips take place during the week-long programme. In September 2012, the Festival was hosted by the University of Aberdeen, giving the Aberdeen partners in the NeuroFAST project an excellent opportunity to propose an event to discuss the food addiction theme. From the outset, the ambition of the Aberdeen partners was to host an interactive workshop providing the opportunity for genuine dialogue, rather than a more formal lecture format. The 2-hour interactive workshop entitled 'Food Addiction: Fact or Fiction?' was accepted into the festival programme under the general heading of 'Talks and Debates', as a joint initiative between project partners from the University of Aberdeen Rowett Institute and the University of Duisburg-Essen, Germany. The event was described in the programme as follows: 'There are many complex factors which lead to people being overweight or obese, but the basic question is "why do some people eat too much?" Are they addicted to food? Join our international panel of psychiatrists and scientists to explore whether eating food can be so rewarding that it leads to a state of addiction similar to that seen with alcohol and drugs'. The Festival was widely promoted around Aberdeen and the surrounding area and received substantial pre-event publicity from regional newspapers.

\section{Format of the Event}

Over 170 people attended the workshop, and it was listed as being sold out in advance in the Festival online programme. At the outset of the event, it was explained to the audience that this was not going to be a lecture but rather a two-way conversation where the event organisers would explain some of the scientific background that has seen the concept of food addiction take hold, how this has been portrayed in the popular media, how food addiction might be viewed within the context of clinical addictions and why we should probably be cautious in how we attach this label to over-consumption of food. The audience were introduced to the hand-held voting system, through which they would be able to express some of their opinions and appreciate some of the issues involved. As context, the first part of the workshop covered the background to the obesity epidemic, recent changes in our food environment and how this may have affected our eating behaviour and how the topic of food addiction is portrayed in the media. The audience then used their voting sets to answer a number of questions, some of them relating to their views and opinions, such as 'Do you believe that food addiction exists?', and others designed to get them to think about taste preferences, diet choices and their interactions with addictive chemicals, e.g. 'Did you like the taste of beer when you first tried it?'. This activity was intended to foster a better under- 
standing of the concept of how appetite and eating are controlled [6], through reflection on personal experience in our current food and drink environment. The feedback from the event (see below) indicated that this part of the event was highly appreciated by the audience.

Outcomes of First Round of Voting: 65\% of the audience who voted thought that food addiction existed. When questioned about their personal dietary experiences, $60 \%$ agreed that they had a 'sweet tooth', but only one third regularly took sugar in tea and coffee, and just over one half either regularly or occasionally drank soft drinks containing sugar. Half of respondents claimed to know how much sugar was in a regular can of soft drink. About $40 \%$ of people voting had given up sugar in tea or coffee at some point, and most had found it easy. About half the audience currently drank beer, and $85 \%$ of respondents did not like the taste of beer when they first tried it.

Food addiction was then addressed from a psychiatrist's perspective, with an explanation of how substance use disorders are currently defined in diagnostic classification schemes [7]. According to these, addiction only applies to such substance use disorders. Applying this current strict definition of chemical addiction to food and its potentially addictive properties highlighted the difficulty inherent in diagnosing any individual as being addicted to food. If, however, behavioural addictions can be diagnosed as is currently being discussed, the term 'food addiction' may be applicable to a small subgroup of individuals, particularly those suffering from binge-eating disorder. Following a second voting session around the subject of behavioural addiction and the likely contribution of food addiction to the obesity problem, the workshop finished with an assessment of the biology linking food consumption and addiction [8], including an evolutionary perspective and brain imaging data [9]. This was followed by an open discussion session with questions from the audience, and an interactive challenge looking at the amount of sugar and fat in some common foods, during which there were informal one-to-one conversations between the NeuroFAST scientists and members of the audience.

Outcomes of Second Round of Voting: 80\% of respondents considered that behavioural addiction exists, but the audience was evenly divided on whether food addiction makes a major contribution to the obesity problem. There was a similar outcome when the audience were asked whether they thought that they or someone they knew were addicted to food (yes 43\%: no 45\%: undecided 12\%).

\section{Lessons Learned - a Perspective from the Audience}

Audience participation was encouraged from the outset when it was made clear that one of the aims was to have discussion and involvement as opposed to giving a dry talk. The presentation seemed to be pitched at about the right level, and the informal, sometimes lighthearted approach of the presenters was easy to relate to and seemed to engage the audience, who responded to the jokes and followed the discussion. The hand voting sets allowed a consistent proportion of the audience to respond to the questions being asked. A number of hypothetical case studies were discussed to demonstrate the diversity of routes toward overweight and obesity, and what role, if any, food addiction might play in this. The audience was invited to indicate, by show of hands, whether they thought that the individuals described in these case studies (e.g. individuals with identified genetic mutations) could be addicted to food. This was followed by informal discussion between the presenter and the audience, and amongst the audience itself. In future we might structure this interaction better, for example by initial use of the voting sets, in a way that audience participants are not discouraged by any implication that their initial response was wrong. What then followed was information about the clinical definition of chemical addiction which raised awareness within the audience 
about what was currently meant by the term addiction, and where behavioural addiction might be integrated in the future. Although effort was made to clarify addiction based on the Diagnostic and Statistical Manual for Mental Disorders (DSM IV TR; American Psychiatric Association) and upcoming DSM-5 criteria used for clinical diagnosis, more time could have been devoted to this key area [7]. There appeared to be a realisation in the audience of the complexities of the situation, and there would have been scope to follow this up, for example, by going back to reassess and discuss with the audience the obesity case studies considered earlier. Another area where a clearer contrast could have been drawn between chemical addiction and food addiction as a behavioural phenotype was in the definition of clinical withdrawal symptoms and the physiological responses that might be termed 'withdrawal symptoms' on a particular weight loss diet. A key issue, for increased emphasis, is that the body needs food for survival, and that abstinence is not an option, in contrast to the lifestyle changes recommended for chemical addiction. The need for food and various nutrients is different from the need/desire/compulsion to overeat. It might also have been useful to summarise how addiction, if relevant to food consumption, would need to be defined (i.e. above a certain level of consumption) and how treatment would have to differ from current clinical addictions.

\section{'What's in Your Food?' Activity}

This event was based around getting members of the audience to estimate, using the simple visual device of sugar lumps and individual butter portions, the amounts of sugar and fat in everyday foods and drinks. The visual demonstration of the quantity of sugar in a can of soft drink earlier in the workshop seemed to shock a lot of the audience. During the interactive activity this led to the discussion of portion size and general consideration of alternatives. These messages appeared to resonate with the participants in the activity. There was also shock at how much sugar was actually allowed according to Guideline Daily Amounts in the UK, and here portion size became an important element of the discussion. People seemed to be aware of which foodstuffs were relatively high in sugar or fat, but had little concept of the quantities of each that this translated into, and consequently appreciated the visual representation of sugar and fat content from the different food groups.

\section{Evaluation}

The event was evaluated by feedback forms. 121 participants completed the forms, the majority of whom were in the age range 19-40 years. Over $80 \%$ of the respondents reported that they found the event enjoyable and interesting. Slightly less (around 70\%) said it was what they had expected when they booked to attend. The overwhelming majority of respondents (90\%) said they had learned something new, and $80 \%$ said that they thought it was relevant to their own life. In response to the question 'What did you enjoy most about the event?', answers included the following: 'the interactive element'; 'info and questions'; 'interesting talk'; 'raised lots of interesting questions'; 'well presented'; 'the interactive voting'; 'accessible to all, well paced, good overview'; 'information which was light and informal'. It is clear that the style of the presenters, being able to bring in some humour and a variety of styles, is important to the success of this type of event. 


\section{Conclusions}

There is clearly a public appetite for engagement events such as the one described here. In particular, events related to real-life health issues such as obesity, and diet and nutrition, are well received. However, this was not just a public engagement event but one in a topic area of contention, with a high profile in the media in recent years, where participants were quite likely to already have an opinion, and more than likely a strongly held opinion. Under these circumstances, a formal lecture would probably have been inappropriate, and breaking the workshop down into different components with a number of opportunities for the audience to enter into the 'conversation' was a successful formula and appeared to keep the audience's attention. The audience appeared to be receptive to new information and clarification of issues, making it a positive experience for both presenters and, as judged by evaluation, the audience, although it is obviously difficult to judge whether any audience members went away with a changed opinion. Whereas the workshop covered the primary issues of concern in the use of the term 'food addiction' by summarising the arguments for or against a convergence between overeating and drug and alcohol addiction, many of the audience still felt that either they or someone they knew were addicted to food. Another point of discussion could have been whether the use of such terminology is helpful or stigmatizing to people with overeating and weight problems looking for practical solutions in their everyday lives. The food composition activity was intended to provide some help in this direction.

\section{Acknowledgements}

The authors were funded by the European Community's 7th Framework Programme under grant agreement 245009 (NeuroFAST) and the Scottish Government.

\section{Disclosure Statement}

The authors declared no conflict of interest.

\section{References}

1 Bennet DJ, Jennings RC (eds): Successful Science Communication: Telling It like It Is. Cambridge, Cambridge University Press, 2011.

2 Communicating EU Research \& Innovation - a Guide for Project Participants. Luxembourg, Publications Office of the European Union, 2012, ISBN 978-92-79-25639-4.

- 3 Mercer JG, Bird SP: NeuroFAST - the integrated neurobiology of food intake, addiction and stress. Obes Facts 2012;5:293-297.

4 Nogueiras R, Romero A, Vazquez MJ, Novelle MG, López M, Diéguez C: The opioid system and food intake: homeostatic and hedonic mechanisms. Obes Facts 2012;5:196-207.

5 Menzies JRW, Dickson SL, Leng G: Neural substrates underlying interactions between appetite, stress and reward. Obes Facts 2012;5:208-220.

- 6 Pandit R, Mercer JG, Overduin J, la Fleur SE, Adan RAH: Dietary factors affect food reward and motivation to eat. Obes Facts 2012;5:221-242.

- 7 Albayrak 0, Wölfle SM, Hebebrand J: Does food addiction exist? A phenomenological discussion based on the psychiatric classification of substance related disorders and addiction. Obes Facts 2012;5:165-179.

- 8 de Jong JW, Vanderschuren LJMJ, Adan RAH: Towards an animal model of food addiction. Obes Facts 2012;5: 180-195.

9 Iozzo P, Guiducci L, Guzzardi MA, Pagotto U: Brain PET imaging in obesity and food addiction: current evidence and hypothesis. Obes Facts 2012;5:155-164. 